\title{
ERRATUM
}

\section{Inhibition of motility by NEO100 through the calpain-1/RhoA pathway}

TO THE READERSHIP: An error appeared in the article by Marín-Ramos et al. (Marín-Ramos NI, PérezHernández M, Tam A, et al: Inhibition of motility by NEO100 through the calpain-1/RhoA pathway. J Neurosurg [epub ahead of print August 16, 2019; DOI: 10.3171/ 2019.5.JNS19798]).

The abbreviation "GMP" was mistakenly defined as "guanosine monophosphate." The correct definition is "good manufacturing practices." This error appears in the Results section of the abstract, and in the second paragraph of the introductory text. Both sentences are correctly shown below.

Here, the authors show how NEO100, a highly purified good manufacturing practices-quality form of perillyl alcohol, is cytotoxic for different subtypes of GSCs, regardless of the mechanisms of DNA repair present.

NEO100 is a purified good manufacturing practices (GMP)-quality form of perillyl alcohol (POH), a naturally occurring monoterpene isolated from the essential oils of several plants.

The article has been corrected online as of October 11, 2019.

Gillian Shasby
Director of Publications
Journal of Neurosurgery Publishing Group, Charlottesville, VA

CORRESPONDING ARTICLE See pp 1020-1031.

INCLUDE WHEN CITING

Published online October 11, 2019; DOI: 10.3171/2019.9.JNS19798a.

CAANS 2020, except where prohibited by US copyright law 